\title{
neofilolog
}

\author{
Czasopismo Polskiego Towarzystwa Neofilologicznego \\ ISSN 1429-2173, 2019, NR 52/1, 75-88 \\ http://dx.doi.org/10.14746/n.2019.52.1.7 \\ http://poltowneo.org/
}

\author{
Danuta Wiśniewska \\ Adam Mickiewicz University in Poznań \\ https://orcid.org/0000-0002-1168-0967 \\ wis@amu.edu.pl
}

\section{EMOTIONS, LINGUISTIC LANDSCAPE AND LANGUAGE LEARNING}

\begin{abstract}
Emotions are a significant part of our lives. The question of how to communicate emotions is especially important for individuals who, apart from speaking their mother tongue, speak another, either second or foreign language. Research shows that there are differences across languages in terms of the vocabulary of emotion, in the concepts underlying lexical items, in the degree of ease of expressing and describing emotions. Therefore, teaching emotion words is of vital importance for successful communication. One of the factors which may be conducive in eliciting emotions is teaching materials. The purpose of this paper is to address the problem of expressing emotions in a foreign language and suggest the use of linguistic landscape as one of possible sources of input for teaching/learning how to perceive and communicate emotions in a foreign language effectively.
\end{abstract}

Keywords: emotions, emotion words, foreign language learning, linguistic landscape

Słowa kluczowe: emocje, słowa emocjonalne, uczenie się języka obcego, krajobraz językowy

He was confused, painfully conscious of his inarticulateness. He had felt the bigness and glow of life in what he had read, but his speech was inadequate. He could not express what he felt, and to himself he likened himself to a sailor, in a strange ship, on a dark night, groping about in the unfamiliar running rigging. (Martin Eden, Jack London) 


\section{Introduction}

Emotions are part of our lives, whether private or professional, and arise due to a variety of factors while we relate to the world, other people, situations, events, objects. They are one of the burning issues in foreign language learning and teaching, with numerous research studies on the role of positive and negative affective factors that are part and parcel of students' learning and teachers' work (e.g. Arnold, 1999; Gabryś-Barker, Bielska, 2013). Additionally to the question of emotions experienced during life and, more specifically, during education, there is the question of how to communicate affective states in a foreign language, especially as it has been confirmed that talking about emotions in L2 is more difficult or different than in L1 (e.g. Dewaele, 2006, 2008; Dewaele, Nakano, 2012; Pavlenko, 2006).

In line with the current trend of linking classroom education with outof-class opportunities for language learning, recently there has been some interest in the environment, equipped with linguistic signs of different types, such as street signs, banners, billboards, digital signage, barn advertisements, truckside or bus advertising, street furniture, lawn signs, mobile signs, together known to create the linguistic landscape (LL) of a given place. As some scholars suggest, the linguistic landscape may contribute a lot to foreign language learning (Cenoz, Gorter, 2008; Bever, 2012, Dagenais et al., 2014; Aladjem, Jou, 2016), first of all as an "additional source of input in second language acquisition" (Cenoz, Gorter, 2008: 267). Cenoz and Gorter discuss the potential role of the $\mathrm{LL}$ in language teaching in more detail. First, they view the LL as input for SLA which is authentic and contextualised, being a part of the social context in which learning takes place. It is authentic, in the sense that its particular elements have not been created for pedagogical purposes but for real communication and include written messages for potential readers. The language of the LL is usually simple, with limited number of words and simplified sentence structures. However, due to the fact that the texts visible in the LL have diverse functions, they may serve as a basis for the discussion of the intent of the written texts, as well as of the different genres which constitute the LL. Hence, the LL may play a role in the development of pragmatic competence. The LL offers written texts, which makes it suitable for the development of literacy skills and pre-literacy skills, such as print awareness, especially important for younger learners. The linguistic signs placed in the environment are often written, not in one but in two or more languages and, additionally, the verbal message is supported by a complementary visual image. This creates opportunities for practicing reading comprehension and fostering interpretation skills in more than one language, and in more than one mode of communication (not only verbal but 
also visual). Finally, Cenoz and Gorter discuss how the $L L$ is related to affective factors in language learning, especially to attitudes learners have towards languages and to the problem of the identity of speakers of different languages. Obviously, the possibilities for making use of the elements of the LL for foreign language teaching/learning are more numerous, Cenoz and Gorter mention only some basic directions. In this article I would like to look more closely at the linguistic landscape as input to the teaching/learning how to express and communicate emotions in a foreign language.

\section{Emotions}

Emotions have been studied at least since Aristotle's times, and for both philosophers and psychologists they have been a matter of confusion and contradiction. In the $20^{\text {th }}$ century, emotions attracted the interest of scholars working within a variety of academic disciplines, such as sociology, psychology, neurophysiology and linguistics, yet it is still difficult to provide an exhaustive definition of the phenomenon. As Fehr and Russell (1984:464) observed, "[E]veryone knows what an emotion is, until asked to give a definition". Similarly, in the field of language education, Swain (2013:205) wrote: “(...) emotions are the elephants in the room - poorly studied, poorly understood, seen as inferior to rational thought." Most scholars, however, agree that emotion is a wide concept which embraces a whole range of meanings and cannot be reduced to "feelings" only, although, on the other hand, they may be considered in reference to feelings (Wierzbicka, 1995:24). In the studies on emotions, apart from feelings, other phenomena are considered as well, such as changes in control over one's behaviour or thoughts, impulsive, incidental behaviours, the emergence or stability of beliefs, changes in relation to others and physiological changes which are not caused by physiological conditions (Frijda, 2008).

Nico Frijda, in his seminal book The Emotions, wrote:

Emotional phenomena are noninstrumental behaviors and noninstrumental features of behavior, physiological changes, and evaluative, subject-related experiences, as evoked by external or mental events, and primarily by the significance of such events. (1986:4)

What does this brief statement tell us about emotions? First, emotion arises as a consequence of events which are significant for a person, wherein the events are situated in the outer world or, on the contrary, are mental. Among the conditions under which the emotions are elicited, Frijda (1993:225) elsewhere mentions interaction between events and a person's ideals concerning her or 
his welfare, as well as the perceived ability to cope with the event. Second, the emotions arise as a result of an evaluation of the event in relation to the subject's experience and concerns (Scherer, 2005). In fact, evaluation plays a crucial role in the arousal of emotions since it is believed to mediate between events and emotions (Frijda, 1993). It also accounts for the differences in individuals' emotions and between different types of emotions. Smith and Lazarus (1993) explain the phenomenon of appraisal in the following way:

Appraisal is an evaluation of what one's relationship to the environment implies to person well-being. Each positive emotion is said to be produced by a particular kind of appraised benefit, and each negative emotion by a particular kind of appraised harm. The emotional response is hypothesized to prepare and mobilize the person to cope with the particular appraised harm or benefit in an adaptive manner, that is, to avoid, minimize, or alleviate an appraised harm, or to seek, maximize, or maintain an appraised benefit. (Smith, Lazarus, 1993: 234)

Emotions are generated by appraisals, and through appraisals they are connected to actions, impulsive, without prior intent, or intentional (Frijda, 2010). Thus, taking into account both the psychological and social aspects of emotions, they may be considered as mediating between preceding events and their consequences, be they mental or behavioural.

Emotions play a key role in individuals' lives and, what is more, are crucial in relations between individuals, therefore we need words to express and/or describe emotional experiences, whether we speak in our mother tongue or in a second or foreign language. I will discuss emotion words in the next section.

\section{Emotion words}

Emotions are expressed and communicated through language. Expressing emotions and describing emotions is done by speakers not only in literary works, but in their daily discourses by means of linguistic expressions. One of the tools for the communication of emotions, recently discussed in the literature on emotions in bi/multilingual contexts, are emotion words, that is words which indicate or describe affective states and processes, or sometimes evoke emotional responses (Pavlenko, 2008:148).

Languages differ in their range of emotion words. Some have only a few, for example, Chewong is said to have only seven emotion words (Howell, 1981), while others possess a fairly big repertoire, such as English, which is reported to have more than 2,000 emotion words (Wallace, Carson, 1973). Languages differ also in respect to the grammatical categories used for encoding 
emotion. In English, emotions are encoded mainly through nouns and adjectives, while in Polish verbs are preferred (Pavlenko, 2008). Additionally, emotion words are culturally dependent, and it is not always possible to find equivalents in a second language which would provide exactly the same meaning. Wierzbicka and Harkins, discussing the subtle differences between the English label for anger and French words often used as its equivalents, coleré and furieux, explain:

Even in the case of these two fairly closely related European languages, it is widely perceived that the differences in usage of emotion words are connected in some way with cultural attitudes and cultural identity. The different "feel" of the words angry, furious, furieux has much to do with the kinds of things English and French speakers do, how they look, sound and behave, when they feel these emotions. (Wierzbicka, Harkins, 2001:3)

The research on emotion words has revealed that there is a difference between the use of emotion words in the mother tongue (L1) and in language learned post-puberty (L2). First, in L1 discourse the speakers use more emotion words than in L2 (Dewaele, Pavlenko, 2002). Dewaele (2005) provides an overview of psychological research in which it appeared that children reacted better to taboo words or reprimands in L1 than in L2 (Harris, Ayçiçegi, Gleason, 2003). Further, it has been shown that autobiographical narrations in L1 are more vivid than those in L2 (Schrauf, 2000). In addition, $L 2$ is used less frequently for expressing emotions, since it is perceived as a language of distance and detachment (Dewaele, Pavlenko, 2002; Kinginger, 2004; Dewaele, Salomidou, 2017; Basnight-Brown, Altarriba, 2018).

This brief characteristic of emotion words explains the reasons for the concern about these words in foreign language teaching, especially that not much attention so far has been paid to the issue of the ability to communicate emotions, experienced in- and out-of-the classroom.

\section{Emotions in language learning}

The ability to communicate emotions in L2 is not less important than the knowledge of grammar rules, vocabulary lists or correct pronunciation of words. The knowledge of how emotions are communicated in the language we learn as a second/foreign language is necessary in order to understand and interpret properly the language behaviour of our foreign interlocutors, to understand the news reported on TV or in the newspapers, not to speak of works of art, books, films, poetry. The ability to communicate emotions in the language we learn is necessary not only to be understood well by speakers of the target language, but also, or maybe first of all, to broaden the areas in which we could express ourselves. 
Although it is not necessary for learners to identify with target language speakers, they should at least be aware of the diverse ways of marking emotion. Dewaele (2005) in one of his articles desperately asks the following questions:

Why then are they [emotions] so conspicuously absent in foreign language teaching material-and, possibly as a consequence - so infrequent in L2 users' interlanguage (cf. Dewaele \& Pavlenko, 2002)? Don't learners need to be able to express and recognize anger, sadness, shame, happiness in the L2? Moreover, because the vocabulary of emotions and emotion scripts are different from language to language, it seems doubly important to focus on the differences and similarities between the L 1(s) and the L2. (Dewaele, 2005:8)

If we accept that there are differences in the perception and expression of emotions in L1 and L2, and if we agree with Dewaele that we need to help the learners express themselves, it means that to this end we need to equip the learners with linguistic, sociopragmatic and sociocultural resources as well as to raise the learners' awareness that communication with others often involves emotional load (Dewaele, 2005: 377).

Dewaele and Pavlenko (2002) examined five factors that may influence the use of emotion words in L2. The first factor was sociocultural competence, in the words of the authors "the ability to identify, categorize, perceive, and engage in verbal and nonverbal behaviors similarly to other members of a particular speech community" (Dewaele, Pavlenko 2002: 268). The findings of the research showed that familiarity with socio-cultural context affects the choice of emotion vocabulary but not the amount of it. The second factor was language proficiency. Higher language proficiency increased the frequency of the use of emotion words. The results concerning the relation between gender and the use of emotion words were not unequivocal. Generally, the authors assume that it is the gender ideology and the value of emotion speech, the context of the interaction and the identity of conversation participants that influence the frequency and choice of emotion words. Research into extroversion, a variable often studied in $\mathrm{FL} / \mathrm{SL}$, confirmed that extrovert learners use emotion words more readily. Finally, the results of research into the role of the type of material used for eliciting emotion words underscores the need to consider and investigate the relation between emotionality of the topic and the use of emotion words.

The results of this research, or rather series of research studies may be interesting not only for researchers, but also, in more practical terms, for foreign language teachers. As follows from the research results quoted above, a significant factor in eliciting emotion vocabulary is the topics and materials. Some suggestions concerning this issue will be presented in the following section. 


\section{The linguistic landscape and emotions}

The modern world seems to offer a multiplicity of opportunities for both formal and informal language learning on the basis of the language that is visible or heard in the environment, including traditional and new media, travels abroad and foreign language displayed in public spaces, i.e. spaces either fully available to everybody, for example, streets, squares and roads, or partially, under certain conditions, such as libraries, museums and schools. The public display of languages has predominantly been of interest for studies on the linguistic landscape understood as "[T]he language of public road signs, advertising billboards, street names, place names, commercial shop signs, and public signs on government buildings combines to form the linguistic landscape of a given territory, region, or urban agglomeration" (Landry, Bourhis 1997:25). The studies of the linguistic landscape have been primarily conducted within sociolinguistic and semiotic fields seeking correlations between language use and social class, social attributes (religion, ethnicity, race), language policy, social movements or economy. Far fewer studies have attempted to research the linguistic landscape as a potentially supportive environment for language learning. However, in both theoretical considerations and research reports, the linguistic landscape has been advocated as a valuable resource for authentic language (Cenoz, Gorter, 2008; Sayer, 2010), helpful in the acquisition of critical literacy skills (Chern, Dooley, 2014), development of language awareness, pragmatic competence and multicompetence, i.e. multilingual and visual competence combined (Cenoz, Gorter, 2008). The focus on the linguistic landscape seems to be particularly suitable for the development of language awareness and pragmatic competence. The ability to create texts and to understand the intentions of the authors of texts displayed in the environment are equally important. These publicly visible texts perform different functions, both informative (e.g. directions, tourist information, instructions) as well as symbolic (e.g. marking power, referring to specific values, indicating group identity). The analysis of linguistic landscape items and their functions may foster and enrich classroom language learning. Similarly, as Dagenais et al. (2009: 258) suggest, the reference to the local linguistic landscape may "contextualize language awareness activities at school" and make them "more meaningful" for children. These activities may aim at an understanding and appreciation of linguistic diversity, comparing the languages seen or heard in the immediate environment, exploring the social functions of languages. Additionally, relating classroom activities to the local, outside world makes the learning more practical and purposeful. The linguistic signs present in the environment offer opportunities for including the emotional aspect in 
language learning/teaching, especially as writing (written texts are at least one component of the linguistic landscape) is considered "a powerful tool for generating emotional experiences" (Hinojosa et al., 2010:748). Some signs in the LL include emotional content, others are neutral. One way of approaching emotions involves the reading and interpretation of a sign with a focus on what means have been used to achieve its emotional "flavour," which may lead to building an awareness of the linguistic and other resources used to achieve emotional content. Responding to the sign (talking about perceptions, expressing one's thoughts and feelings about the content of the sign) in the linguistic landscape, which requires further work on lexis, semantics, syntax, and maybe also on nonverbal behaviour, is another way of practicing emotion words.

In the following section, three examples of the use of LL items for the practice of emotion words will be provided.

\section{The linguistic landscape, emotions and language learning: example tasks}

The LL is composed of written signs many of which could be adapted for classroom practice. The examples of such signs include, among others, advertising signs which appeal to client emotions; political banners or banners carried in various demonstrations which often elicit contradictory emotions; banners and other signs used in sporting events which are not devoid of emotions; graffiti which is an expression of contestation; monuments which memorialise tragic events, and many others. All of them, presumably, could serve as a starting point for learning new lexical items, identifying the concepts behind these words, comparison of emotion words across languages and cultures, and a variety of communicative tasks.

In the examples below, I begin by briefly describing an item which is a part of the $L L$ and then suggest some activities which might be performed in the classroom. Beforehand, the linguistic items should be photographed by the students and/or the teacher in their environment and brought into the classroom, if possible. If not, they may be accessed via the Internet, newspapers and magazines, or postcards. The first example of double place names is one of many of that kind which can be found in Poland, and in many other countries. The linguistic items suggested in the second example may be more difficult to capture because of their temporary nature. Such temporary banners are used not only in political demonstrations, but also in sporting or entertainment events, solidarity demonstrations and others. The final example is based on advertising posters because they are numerous, and hence readily available, and their primary goal is to appeal to the readers' attention and emotions. Needless to say that the activities suggested below should be adjusted to 
the students' age and language proficiency level, however they are most suitable for intermediate or advanced learners.

\section{Example 1. Minority languages and attitudes}

The languages used in the public space have not only an informational but also a symbolic function. The presence of minority languages in addition to the official language of the country has a symbolic function related to the sense of identity of that minority and their feelings about themselves and their language (Cenoz, Gorter, 2006). In some cases, however, the coexistence of both languages, official and minority, in one place causes problems. Let us take the example of Opole and the surrounding region where in certain towns and villages the place names are written both in Polish and in German, as a consequence of the history of that region and current legal regulations concerning the languages of ethnic minorities. In fact, double place names are not novel there, since as early as in the Middle Ages German or Latin names appeared next to the Polish names. Now, after a period of the policy of using only Polish names, and after a period of the illegal placement of German names, the regulations of $\mathbf{2 0 0 5}$ allow the use of Polish and German names for towns, villages, in streets signs and names of offices under precisely determined conditions (Choroś, 2017). Although double-naming, as observed by Choroś, has in this case only a symbolic, emotional value for the minority, at times it becomes a source of conflict for both Polish and German inhabitants, manifested by the erasure of either German or Polish names from sign posts. How can we use the linguistic landscape of an area where a conflict between minority and majority ethnic groups is visible for teaching the language of emotions? Suggested tasks include:

Vocabulary practice: In the study of emotional reactions to ethnic minorities (Dijker, 1987: 313) the following list of emotion words has been compiled: happiness, curiosity, admiration, sympathy, liking, attractiveness, impulse to seek contact, annoyance, aversion, oddity, anger, fear, uncertainty, distrust, contempt, ugliness, antipathy, impulse to physical aggression, to verbal aggression, to keep distance, mental unfriendliness, wish that the object would move. Learner task: Group words appropriate to this situation and those which are not appropriate. Justify your decisions.

Speaking: Explain how each of the emotions listed above would be/could be manifested in social life. What behaviours/actions could be induced by these emotions? Role play: Take on the role of a member of each ethnic group; get familiar with how each group reveals their emotions; act out a conflicting/friendly situation. Writing: Write a letter/essay/blog about how you feel about double names and their erasure. 
Example 2. Political unrest - anger or feeling good?

The items of the linguistic landscape range from those that have been fixed for years or even centuries, such as inscriptions on old monuments, houses or churches, to relatively stable examples, though not as historic, such as shop signboards, advertising billboards or street signs, to occasional ones, for example those which are used in social protests against the state, state policy and the state economy. These items are usually banners with slogans, graffiti, scribblings on city walls. The content of the texts mirrors the emotions of those who are their authors, as well as those who distribute them to others, or hold them. Their function is to evoke an emotional response from the onlookers. The aim of the activities is by no means to encourage the students to participate in riots or to take photos, instead we/they may bring to the classroom books, pictures, newspapers or may use the internet as a valuable source of data concerning current and past events. Political events which are well documented, also concerning the LL of the streets, include, for example, Brexit, the Icelandic economic protests, the Chilean students' protests, the Polish Orange Alternative protests, and others. How can we use the linguistic landscape of political unrest for teaching the language of emotions?

Reading: Students identify languages on banners, read the texts and interpret them, also taking into consideration non-verbal cues.

Discussion: Why are these people protesting? What emotions have them made protest? How would you feel if you were one of the protesting people? Listening: Listen to an interview with the protesters. Can you judge what their emotions are: anxiety, frustration, outrage, sympathy, compassion, fear, shame, pleasure, anger? What are your feelings towards the protesters?

Example 3. Charity advertising - between compassion and joy

Charity advertisements are omnipresent in society. They appeal through image and text to the emotions, in order to encourage some action/donation on the part of the viewer. The majority of charity campaigns use outdoor advertising, billboards, posters, walls, buses and trains. This type of advertising aims at eliciting a wide range of mixed emotions, both positive and negative, to exert strong influence on the viewer/reader and make him or her attentive to the content and respond readily (Lee, 2010).

How can we use charity advertising for teaching the language of emotions?: Attention to multimodality: analysis of the modes in which the message is conveyed - verbal and visual. How do they combine in order to deliver the message? How do they combine to persuade the reader/viewer to take action? Which mode is more forceful in eliciting emotions? 
Speaking: What kind of emotions do you experience when you pass a charity advertisement? Which prevail, positive or negative? Why? What are the feelings of those for whom the campaign has been created? Collect advertisements from different countries which have similar aims. Compare their contents. Do they appeal to the same emotions? Do they use the same means? Writing: Describe a charity advertisement in L1 and L2, maybe also in L3. Analyse similarities and differences in your descriptions. Analyse problems in expressing your feelings in any of these languages. Rewrite if necessary.

\section{Conclusions}

To sum up, in this article I have attempted to show that there is a need to include a wider range of $L 2$ emotion words in the teaching of a foreign language, since emotions play a substantial role in our lives. The ability to speak about emotions and to express the emotions that an individual experiences is necessary for successful dialogue between people. Subsequently, I attempted to show that the linguistic landscape may be a valuable source of linguistic input into the teaching/learning of emotion words. The inclusion of linguistic landscape items as additional authentic material for learning will bridge classroom learning with the environment and make learning more context-related. Real artefacts related to real events will be likely to be helpful in studying the language of emotions. However, research has to be conducted in order to find answers to the following questions: 1) How can we make use of the linguistic landscape in the teaching of foreign languages effectively, especially in relation to emotion words? 2) Which aspects of the linguistic landscape are most suitable for teaching emotion words? 3) Which aspect of emotion words (sociopragmatic, cultural) is best learned in/through the linguistic landscape?

\section{REFERENCES}

Aladjem R., Jou B. (2016), The linguistic landscape as a learning space for contextual language learning (in) "Journal of Learning Spaces", No 5(2), pp: 66-70.

Arnold, J. (ed.), (1999), Affect in language learning. Cambridge: Cambridge University Press.

Basnight-Brown D.M., Altarriba J. (2018), The influence of emotion and culture on language representation and processing (in) Faucher C. (ed.), Advances in culturally-aware intelligent systems and in cross-cultural psychological studies. Cham: Springer, pp. 415-432.

Bever O. (2012), Linguistic landscapes and environmental print as a resorce for language and literacy development in multilingual contexts (in) Sanz 
M., Igoa, (eds.), Applying language science to language pedagogy. Cambridge: Cambridge Scholars Publishing, pp. 321-342.

Cenoz J., Gorter D. (2006), Linguistic landscape and minority languages (in) "The International Journal of Multilingualism", No 3, pp. 67-80.

Cenoz J., Gorter D. (2008), The linguistic landscape as an additional source of input in second language acquisition in "IRAL", No 46, pp. 267-287.

Chern Ch-I., Dooley, K. (2014), English learning by walking down the street (in) "ELT Journal", No 68(2), pp. 113-123.

Choroś M. (2017), Wprowadzanie podwójnych nazw miejscowości. Rocznik Ziem Zachodnich 01: 360-383.

Dagenais D., Moore D., Sabatier C., Lamarre P., Armand, F. (2014), Linguistic landscape and language awareness (in) Shohamy E., Gorter D. (eds.), Linguistic landscape: Expanding the scenery. London, UK: Routledge, pp. 253-269.

Dewaele J. M. (2005), Investigating the psychological and emotional dimensions in instructed language learning: obstacles and possibilities (in) "The Modern Language Journal", No 89(3), pp. 367-380.

Dewaele J. M. (2006), Expressing anger in multiple languages (in) Pavlenko A. (ed), Bilingual minds: Emotional experience, expression and representation. Clevedon: Multilingual Matters, pp. 118-151.

Dewaele J. M. (2008), The emotional weight of "I love you" in multi-lingual's language (in) "Journal of Pragmatics", No 40, pp. 1753-1780.

Dewaele J. M., Nakano S. (2012), Multilinguals' perceptions of feeling different when switching languages (in) "Journal of Multilingual and Multicultural Development", No 34(2), pp. 107-120.

Dewaele J. M, Pavlenko A. (2002), Emotion vocabulary in interlanguage (in) “Language Learning" 52(2), pp. 263-322.

Dewaele J. M., Salomidou L. (2017), Loving a partner in a foreign language (in) "Journal of Pragmatics", No 108, pp. 116-130.

Dijker A. J. M. (1987), Emotional reactions to ethnic minorities. (in) "European Journal of Social Psychology", No 17(3), 305-325.

Fehr B., Russell J. A. (1984), Concept of emotion viewed from a prototype perspective (in) "Journal of Experimental Psychology", No 113(3), 464-486.

Frijda N. H. (1986), The emotions. Cambridge: Cambridge University Press.

Frijda N. H. (1993), Appraisal and beyond: The issue of cognitive determinants of emotion (in) "Cognition and Emotion" No 7(3/4), pp. 225-392.

Frijda N.H. (2008), The psychologists' point of view. (in) Lewis M., HavilandJones J.M., Feldman Barrett L. (eds.), Handbook of emotions. New YorkLondon: The Guilford Press, pp. 68-87.

Frijda N. H. (2010), Impulsive action and motivation (in) "Biological Psychology", No 84, pp. 570-579. 
Gabryś-Barker D., Bielska J. (eds.), (2013), The affective dimension in second language acquisition. Bristol: Multilingual Matters.

Harris C. L., Ayçiçegi A., Gleason, J.B. (2003), Taboo words and reprimands elicit greater autonomic reactivity in a first than in a second language (in) "Applied Psycholinguistics", No 24, pp. 561-579.

Hinojosa J.A., Méndez-Bértolo, C., Pozo, M.A. (2010), Looking at emotional words is not the same as reading emotional words: behavioral and neural correlates (in) "Psychophysiology", No 47, pp. 748-757.

Howell S. (1981), Rules not words. (in) Heels P., Lock A. (eds.), Indigenous psychologies: The anthropology of the self. San Diego, CA:Academic Press, pp. 133-143. Kinginger C. (2004), Bilingualism and emotion in the autobiographical works of Nancy Huston (in) "Journal of Multilingual and Multicultural Development", No 25, pp. 159-178.

Landry R., Bourhis R.Y. (1997), Linguistic landscape and ethnolinguistic vitality. An empirical study (in) "Journal of Language and Social Psychology", No 16, pp. 23-49.

Lee S.Y. (2010), Ad-induced affect: The effects of forwarning, affect intensity and prior brand attitude. (in) "Journal of Marketing Communications", No 16(4), pp. 225-237.

Pavlenko A. (2006), Bilingual selves (in) Pavlenko A. (ed.), Bilingual minds: Emotional experience, expression, and representation. Clevedon: Multilingual Matters, pp. 1-33.

Pavlenko A. (2008), Emotion and emotion-laden words in the bilingual lexicon (in) "Bilingualism: Language and Cognition", No 11(2), pp. 147-164.

Sayer P. (2010), Using the linguistic landscape as a pedagogical resource (in) "ELT Journal", No 64(2), pp. 143-154.

Scherer K. R. (2005), What are emotions? And how can they be measured? (in) "Social Science Information", No 44(4), pp. 695-729.

Schrauf R. W. (2000), Bilingual autobiographical memory: Experimental studies and clinical cases (in) "Culture and Psychology", No 6, pp. 387-41.

Smith C. A., Lazarus, R. S. (1993), Appraisal Components, Core Relational Themes, and the Emotions (in) "Cognition and Emotion", No 7(3/4), pp. 233-269.

Swain M. (2013), The inseparability of cognition and emotion (in) "Language Teaching", 46(2), pp. 195-207.

Wallace, A., Carson, M. (1973), Sharing and diversity in emotion terminology (in) "Ethos", No 1(1), pp. 1-29.

Wierzbicka A. (1995), Everyday conceptions of emotion: A semantic perspective. (in) Russell J.A., Fernández-Dols, J.M., Manstead, A.S.R., Wellenkamp, J.C. (eds.), Everyday conceptions of emotion: An introduction 
to the psychology, anthropology and linguistics of emotion. Behavioural and social sciences. Dordrecht: Kluwer Academic, vol. 81: pp. 17-47.

Wierzbicka A., Harkins, J. (2001), Introduction (in) Harkins J., Wierzbicka A. (eds.), Emotions in crosslinguistic perspective. Berlin-New York: Mouton de Gruyter, pp. 1-34. 